\author{
Grete Mørk Kindberg \\ Steinar Uran \\ Grete Friisk \\ Ivar Martinsen \\ Tore Skotland
}

\section{The fate of Gd and chelate following intravenous injection of gadodiamide in rats}

Received: 20 October 2009

Revised: 11 December 2009

Accepted: 23 December 2009

Published online: 16 February 2010

(C) The Author(s) 2010.

This article is published with open access at Springerlink.com
Grete Mørk Kindberg and Steinar Uran contributed equally to this work.

G. M. Kindberg $(\bowtie) \cdot$ S. Uran •

G. Friisk - I. Martinsen - T. Skotland

Research and Development,

GE Healthcare,

Nycoveien 2,

0485 Oslo, Norway

e-mail: Grete.Mork.Kindberg@ge.com

Tel.: +47-23-185551

Fax: +47-23-186014
Abstract Objective: The biodistribution of gadolinium $(\mathrm{Gd})$ and chelate was studied in rats injected intravenously with a commercially available gadodiamide magnetic resonance contrast agent spiked with trace amounts of ${ }^{14} \mathrm{C}$-labelled GdDTPABMA. Methods: Biodistribution of the ${ }^{14} \mathrm{C}$-labelled ligand in whole animals was visualised using quantitative whole-body autoradiography, and quantified in individual tissue samples by analysing for radioactivity using beta-counting. Biodistribution of Gd was measured by inductively coupled plasma atomic emission spectroscopy (ICP-AES) and inductively coupled plasma sector field mass spectrometry (ICP-SF-MS). Results: The injected dose was rapidly excreted, with only $1.0 \%$ remaining in the body at $24 \mathrm{~h}$. The radioactivity thereafter was mainly associated with kidney cortex, liver, lung, muscle and skin, with a similar rate of clearance for both ligand and $\mathrm{Gd}$ from these tissues. The ratio between ${ }^{14} \mathrm{C}$-labelled substance and $\mathrm{Gd}$ was not significantly different from that of the injected substance in most tissue samples up to $24 \mathrm{~h}$ after injection; the ratio then slowly decreased. Conclusions: The data clearly show that measurements of Gd concentration alone in tissue samples from animals injected with Gd-based contrast agents (GBCAs) cannot be used as a measure of $\mathrm{Gd}$ released from the ligand. To our knowledge, such measurements comparing $\mathrm{Gd}$ and ligand concentrations and distribution in tissue samples have not been published previously for any of the commercial GBCAs.

Keywords Gadolinium - Contrast agents $\cdot$ Gadodiamide $\cdot$ Stability $\cdot$ Rats

\section{Introduction}

For many years there have been discussions in the literature relating to the stability of gadolinium $(\mathrm{Gd})$ based contrast agents (GBCAs). The recent focus on the rare, but very serious disorder nephrogenic systemic fibrosis (NSF), characterised by fibrosis of the skin and other tissues throughout the body, has led to speculation about the mechanisms involved in the development of this disease, and the role that Gd may play if released from the GBCAs (e.g. see [1-6]). Accordingly, it is of interest to know how much of the Gd in an injected dose of GBCA may be released in the body, e.g. by the process termed dechelation or transmetallation. To our knowledge, there have been no reliable data in the literature to unequivocally demonstrate whether Gd present in tissues is still chelated or separated from the chelate. The aim of the present study was to investigate this area of uncertainty by analysing tissue samples for concentrations of both chelate and $\mathrm{Gd}$ separately following injection of gadodiamide (Omniscan, GE Healthcare, Princeton, N.J., USA) containing ${ }^{14} \mathrm{C}$-labelled GdDTPA-BMA in rats.

The stability of GBCAs has been studied using different analytical methods, but much of the published information is based on in vitro studies performed under conditions that are far from physiological, and several of the in vivo 
studies do not contain sufficient data to support the conclusions drawn. Missing information in such studies includes lack of quality control data for any free Gd in the solutions injected $[7,8]$, interpreting Gd present in tissue samples as being due to Gd released from the GBCAs without measuring the chelate (e.g. [9-12]), or not taking the amount of extra chelate added to the commercial preparations into consideration when interpreting data $[13$, 14]. We therefore initiated a study to investigate the fate of GdDTPA-BMA following intravenous injection in rats using analytical techniques that cannot be used in human studies, such as quantitative whole-body autoradiography (QWBA) and analyses of tissue samples for the content of both DTPA-BMA and Gd. Several strategies are, at least in theory, possible to use in such a study. We have avoided using ${ }^{153} \mathrm{Gd}$ as, from previous experience, we found that it may give radiolysis of DTPA-BMA and lead to misinterpretation of results. For instance, any radiolysis of the sample may complicate the interpretation of the data as dechelation because the chemical instability of the substance may be difficult to differentiate from radiolysis. To avoid this, we radiolabelled the chelate only and injected Omniscan with the addition of trace amounts of $\operatorname{Gd}\left[{ }^{14} \mathrm{C}\right]$ DTPA-BMA intravenously into rats. The content of tissue sample homogenates from selected organs were quantified for the amount of ${ }^{14} \mathrm{C}$ labelled chelate (DTPA-BMA) by using beta-counting, and for Gd using inductively coupled plasma atomic emission spectroscopy (ICP-AES) or inductively coupled plasma sector field mass spectrometry (ICP-SF-MS). Beta-counting was performed on samples combusted in a sample oxidiser, i.e. a process where the radioactivity is transferred into ${ }^{14} \mathrm{CO}_{2}$ and trapped before counting in order to avoid any quenching. QWBA was used to visualise the biodistribution of the ${ }^{14} \mathrm{C}$ labelled chelate in the whole animal.

The data obtained show a very similar rate of clearance for radioactivity and $\mathrm{Gd}$ from most tissues, and that measurements of Gd content in tissue samples cannot be used to estimate the amount of $\mathrm{Gd}$ released from the chelate.

\section{Materials and methods}

Materials

DTPA-BMA was radiolabelled with ${ }^{14} \mathrm{C}$ in the positions shown in the insert of Fig. 1; Gd was added, and the Gd $\left[{ }^{14} \mathrm{C}\right]$ DTPA-BMA obtained had a specific activity of $15 \mathrm{mCi} / \mathrm{mmol}(26.3 \mu \mathrm{Ci} / \mathrm{mg})$. The radiolabelled product was supplied as a dry substance (GE Healthcare, Cardiff, UK). Omniscan, i.e. the commercial agent from GE Healthcare (Princeton, N.J., USA) contains 0.5 m gadodiamide (GdDTPA-BMA) and $0.025 \mathrm{~m}$ caldiamide (CaDTPABMA). All other chemicals used were of analytical quality. Water was purified by reverse osmosis, ion exchanged and filtered through a $0.45-\mu \mathrm{m}$ filter on a Milli-Q Reagent Water System (Millipore, Billerica, Mass., USA).

Quality control and stability of radiolabelled substance

The radiolabelled substance was tested for radiochemical purity using HPLC with online radiochemical detection. An HP 1100 system (Agilent Technologies, Santa Clara, Calif., USA) coupled to a Radiomatic 150TR Flow Scintillation Analyzer (PerkinElmer, Waltham, Mass.) was used with an ACE 3 AQ, $150 \times 4 \mathrm{~mm}$ analytical column (Advanced Chromatography Technologies, Aberdeen, Scotland) operated at $25^{\circ} \mathrm{C}$. The mobile phase was $0.2 \mathrm{M}$ ammonium acetate: acetonitrile; $99: 1(\mathrm{v} / \mathrm{v})$ run isocratic at $0.8 \mathrm{ml} / \mathrm{min}$, and the flow cocktail was Ultima-Flo M (PerkinElmer) run at $2.4 \mathrm{ml} / \mathrm{min}$. The substance was dissolved in sterile water to a radioactive concentration of $2.5 \mathrm{MBq} / \mathrm{ml}$, kept at $6^{\circ} \mathrm{C}$, and $10 \mu \mathrm{l}$ was injected for each analysis. The radiochemical purity was shown to be greater than $98 \%$; no changes in the purity profile could be seen after 6 months storage at either $2-8^{\circ} \mathrm{C}$ or below $-15^{\circ} \mathrm{C}$. A typical chromatogram is shown in Fig. 1.
Fig. 1 Chromatographic profile obtained following HPLC analyses of $\mathrm{Gd}\left[{ }^{14} \mathrm{C}\right] \mathrm{DTPA}$ BMA using a radiochemical detector. The radiochemical purity was estimated to be at least $98 \%$ based on such chromatograms. The ${ }^{14} \mathrm{C}$-labelling positions are shown in the insert (Gd not shown in order to better visualise the labelling positions)

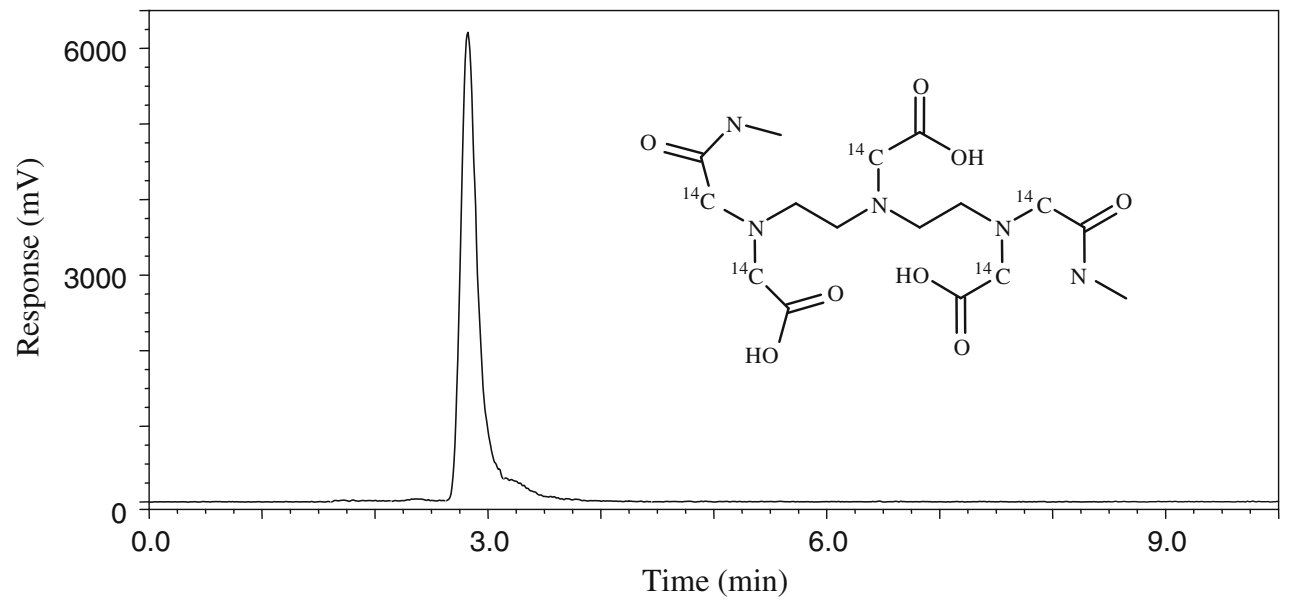


Animals and experimental design

Male Sprague Dawley rats, weighing 165-205 g, were obtained from Scanbur, Sweden. The animals were identified by numbered ear tags and kept in polycarbonate cages (two per cage). The rats were housed in an animal room with a light/dark cycle of $12 \mathrm{~h}$, temperature $21 \pm 2^{\circ} \mathrm{C}$ and relative humidity of $55 \pm 10 \%$. They had access ad libitum to municipally supplied tap water and Rat and Mouse No. 1 Maintenance Diet (RM1) from Special Diet Services, UK. All animal experiments complied with local legal requirements and internal guidelines.

Fifteen rats were randomly allocated to five groups, each containing three rats. The rats were anaesthetised by isoflurane to surgical level and injected intravenously into a lateral tail vein with Omniscan containing trace amounts of $\mathrm{Gd}\left[{ }^{14} \mathrm{C}\right]$ DTPA-BMA. A dose of $0.5 \mathrm{mmol} \mathrm{Gd} / \mathrm{kg}$ body weight was given to each animal. The injection solution contained $0.404 \mathrm{mmol} / \mathrm{ml}$ GdDTPA-BMA and $0.0202 \mathrm{mmol} / \mathrm{ml}$ CaDTPA-BMA (excess chelate in the Omniscan formulation) and $0.00679 \mathrm{mmol} / \mathrm{ml} \mathrm{Gd}\left[{ }^{14} \mathrm{C}\right] \mathrm{DTPA}-\mathrm{BMA}$. Thus, approximately $1.7 \%$ of the injected Gd was bound to the radiolabelled substance and there was approximately three-times more CaDTPA-BMA present than the added $\mathrm{Gd}\left[{ }^{14} \mathrm{C}\right] \mathrm{DTPA}-\mathrm{BMA}$. The dose administered in this study was $0.5 \mathrm{mmol} / \mathrm{kg}$, compared with a standard clinical dose of $0.1 \mathrm{mmol} / \mathrm{kg}$. At 1 , 4, and $24 \mathrm{~h}$, and 3 and 7 days following injection of the test substance, animals were killed with an overdose of $25 \mathrm{mg} / \mathrm{ml}$ Pentothal Natrium (4 ml/kg b.w.). Each rat was immediately coated with aqueous $2 \%$ carboxymethyl cellulose (CMC), immersed in liquid nitrogen and stored at $-20^{\circ} \mathrm{C}$ until prepared for QWBA analyses.

\section{QWBA}

QWBA analysis was performed as described earlier [15]. In short, the animals were embedded in $2 \%$ carboxymethyl cellulose $(\mathrm{CMC})$, immersed in a hexane/dry ice bath $\left(-80^{\circ} \mathrm{C}\right)$ for $30 \mathrm{~min}$ and frozen overnight at $-20^{\circ} \mathrm{C}$, before sectioning at a thickness of $25 \mu \mathrm{m}$ at three to five different levels. The sections were prepared by using a Leica Cryomicrotome $\mathrm{CM} 3600$ at $-20^{\circ} \mathrm{C}$ and exposed for 7 days to imaging plates (FUJI BAS III Imaging Plates, Japan) before imaging using a Fujifilm BioImager Analyzer BAS 2500 with BASReader Software version 2.21 (Fuji Photo Film). The resulting images were imported into AIDA software version 3.25 (raytest, Straubenhardt, Germany) for quantification. All visible organs were measured and compared with the calibration standards included as detailed previously [15].

\section{Quantification of radioactivity and Gd in tissue samples}

From the part of the animal not used for QWBA (approximately half of each animal), representative sam- ples of liver, kidney, lung, skin, muscle and bone (femur) were dissected out. The bone samples were further separated into bone matrix and bone marrow. The tissue samples from liver (obtained from each of the three animals at each time point) were homogenised, and each homogenate and the tissue samples from the other organs were divided into two replicates, one for determination of $\mathrm{Gd}$ and one for radioactivity. The bone marrow samples were not analysed because too little material was obtained.

The quantification of Gd by ICP-AES and ICP-SF-MS was carried out as follows: 0.3-1 g of liver, kidney, lung, skin and muscle (wet weight) were digested with nitric acid and hydrogen peroxide at $90^{\circ} \mathrm{C}$ for $4 \mathrm{~h}$ in polypropylene tubes. The samples were analysed by using a Perkin Elmer Optima 3300 DV ICP-AES instrument (radial mode) and by using the Gd 336.223-nm emission line for the liver samples and the Gd 342.247-nm emission line for kidney, lung, skin and muscle samples. Scandium was used as an internal standard and analysed by using the $424.683-\mathrm{nm}$ emission line. Quality control samples were prepared by spiking the NIST (National Institute of Standards and Technology, USA) bovine liver SRM 1577b with known amounts of Gd. The accuracy was within the range 102$103 \%$ of added $\mathrm{Gd}$ and the repeatability (within day precision) was within the range $1.0-1.4 \%$ relative standard deviation (RSD). The detection limit was $0.1 \mu \mathrm{g} \mathrm{Gd} / \mathrm{g}$ tissue. The femur bone matrix samples $(0.05-0.2 \mathrm{~g})$ were digested with nitric acid at $90^{\circ} \mathrm{C}$ for $3 \mathrm{~h}$ in polypropylene tubes. Europium was added as an internal standard and the samples were diluted to $50 \mathrm{ml}$. The bone samples were analysed by using a Thermo Finnigan Element2 ICP-SFMS instrument by using the isotopes ${ }^{157} \mathrm{Gd}$ (analyte) and ${ }^{153} \mathrm{Eu}$ (internal standard) in low-resolution mode. Quality control samples were prepared by spiking the NIST bovine liver SRM 1577b and Weifa bone powder (Weifa, Norway) with known amounts of Gd. The accuracy was within the range $101-106 \%$ and the repeatability was within the range $0.3-2.7 \%$ RSD. The detection limit was $0.02 \mu \mathrm{g} \mathrm{Gd} / \mathrm{g}$ tissue.

The radioactivity of the tissue samples was measured following combustion in a sample oxidizer (Model 307 Packard; PerkinElmer Life and Analytical Sciences, Boston, Mass.) and beta-counting using a Packard TriCarb 2700 TR liquid scintillation analyzer (PerkinElmer Life and Analytical Sciences) as described previously [15]. The recovery from the sample oxidiser was found to be $97.5 \pm 0.7 \%$.

The following estimates of relative organ weight $(\mathrm{g} / 100 \mathrm{~g}$ body weight) were used to quantify the percentage of injected dose recovered per organ or tissue as it was not possible to weigh all organs in this study (when measuring radioactivity of tissue samples from the part of the animal not used for QWBA): femur bone matrix 0.4\%; kidney, $1.2 \%$; lung, $1.2 \%$; liver, $4.9 \%$; skin and fur, $18 \%$; muscle, $43 \%$ (GE Healthcare historical data). 


\section{Results}

Representative QWBA pictures obtained 1, 4 and $24 \mathrm{~h}$, and 3 and 7 days after injection of Omniscan with trace amounts of ${ }^{14} \mathrm{C}$-labelled GdDTPA-BMA are shown in Fig. 2. The image obtained $1 \mathrm{~h}$ after injection shows widespread biodistribution as expected for an extracellular contrast agent, rapid urinary excretion was illustrated by high concentrations of radioactivity in the kidney and bladder. Moreover, radioactivity was observed in the oesophagus and intestine. As can be seen from the image taken $4 \mathrm{~h}$ after injection, the radioactivity is rapidly excreted via the urinary tract as previously described [16] with the highest concentration of the radioactivity present in the content of the intestine, the kidney cortex, liver and skin. The images show increased concentrations of the radiolabelled substance in the intervertebral discs of the spinal column (observed up to $24 \mathrm{~h}$ after injection, although visible only in the 1-h image in Fig. 2), in the dermis, and also as a rim surrounding large bones such as the femur although not in the plane of section in the pictures shown; see also data for bone and bone marrow in Table 1). The images obtained at 3 and 7 days after injection show the highest concentration of radioactivity in kidney cortex, but also the presence of radioactivity in some other organs, including skin/fur. The amounts of radioactivity in the different tissues/organs estimated from the QWBA images are detailed in Table 1.

The data obtained after analyses of tissue homogenate samples from kidney, liver, lung, muscle, skin and femur bone matrix are given in Tables 2 and 3. These data were recalculated to be given as percentage of injected dose per organ; such data are shown for the radioactivity in Fig. 3a and for Gd in Fig. 3b; in Fig. 3c the sum of these Gd data and radioactivity data are compared in the same plot. In tissues containing the highest concentrations of radioactivity, there was an excellent agreement between the quantitative radioactivity data obtained with QWBA and beta-counting. For the first four time points the beta-counting data were $105 \pm 7 \%$ (mean \pm standard deviation) of that obtained from QWBA for kidney and $100 \pm 10 \%$ for liver. Lower values obtained with beta-counting of skin and fur compared with QWBA $(69 \pm 10 \%)$ were probably due to the presence of some muscle tissue in the skin and fur homogenates. Similar comparison was not possible for lung and muscle because of the much lower radioactivity present in these tissues; the radioactivity was below the quantification limit in the autoradiography images for muscle by $24 \mathrm{~h}$ after injection (Table 1). As the beta-counting data in general give better sensitivity and accuracy than the QWBA data, and the betacounting data were obtained by analysing the same tissue samples as those used for Gd analyses, it is only the quantitative data obtained after sample oxidation and betacounting that are described and discussed below. The quantitative data obtained with the two techniques were well above the detection limits, i.e. the two analytical methods gave sufficiently robust data.

As can be seen from Fig. 3, the clearance curves for the radioactivity and $\mathrm{Gd}$ are very similar for all tissues analysed and do not show significant differences, except for the femur bone matrix. The data in Fig. 3c show that $0.75 \pm 0.08 \%$ of the injected dose of Gd was present 3 days after injection (sum for kidneys, femurs, liver, lung, muscle and skin) with very similar amounts of DTPA-BMA present in these samples $(0.72 \pm 0.04 \%$ of the injected dose). In samples obtained 7 days after injection, $0.54 \pm$

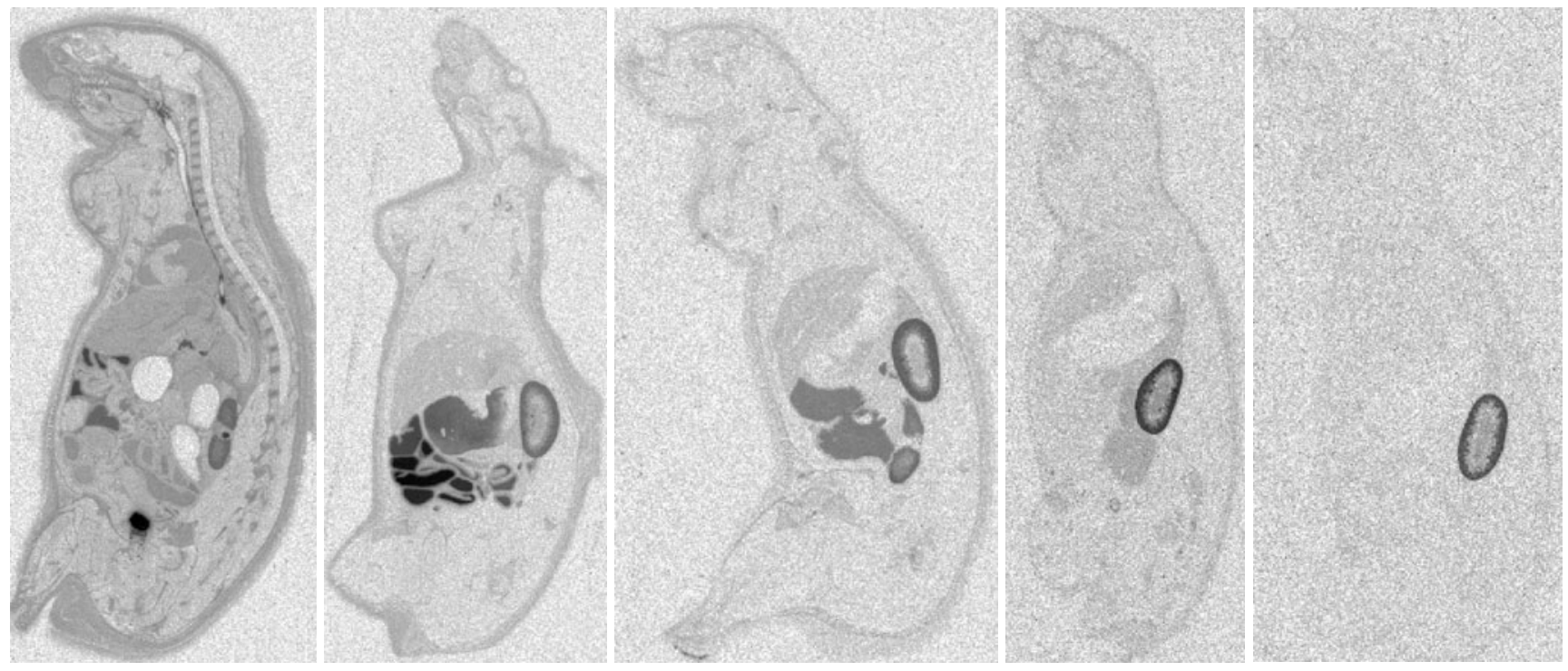

Fig. 2 Representative QWBA pictures obtained of rats 1, 4 and 24 h, and 3 and 7 days (from left to right) after injection of Omniscan with trace amounts of $\operatorname{Gd}\left[{ }^{14} \mathrm{C}\right] \mathrm{DTPA}-\mathrm{BMA}$. See the Materials and methods section for further details 
Table 1 Mean estimated amounts of ${ }^{14} \mathrm{C}$-labelled substance in selected organs/tissues $(\mathrm{kBq} / \mathrm{g}$ tissue) based on the QWBA pictures for rats injected with Omniscan with trace amounts of ${ }^{14} \mathrm{C}$-labelled GdDTPA-BMA ( $D L$ detection limit)

\begin{tabular}{|c|c|c|c|c|c|}
\hline \multirow[t]{2}{*}{ Tissues } & \multicolumn{5}{|c|}{ Time after injection } \\
\hline & $1 \mathrm{~h}$ & $4 \mathrm{~h}$ & $24 \mathrm{~h}$ & 3 days & 7 days \\
\hline Adrenal & 0.40 & 0.09 & 0.08 & 0.04 & 0.04 \\
\hline Blood & 0.85 & 0.03 & $<\mathrm{DL}$ & $<\mathrm{DL}$ & $<\mathrm{DL}$ \\
\hline Blood vessel wall & 0.83 & 0.06 & 0.04 & 0.03 & $<\mathrm{DL}$ \\
\hline Bone & 0.09 & 0.02 & 0.02 & $<\mathrm{DL}$ & $<\mathrm{DL}$ \\
\hline Bone marrow & 0.26 & 0.13 & 0.08 & 0.04 & $<\mathrm{DL}$ \\
\hline Brain & 0.05 & 0.02 & $<\mathrm{DL}$ & $<\mathrm{DL}$ & $<\mathrm{DL}$ \\
\hline Eye & 0.38 & 0.11 & $<\mathrm{DL}$ & $<\mathrm{DL}$ & $<\mathrm{DL}$ \\
\hline Fat (brown) & 0.32 & 0.05 & 0.04 & 0.02 & $<\mathrm{DL}$ \\
\hline Heart & 0.31 & 0.03 & 0.02 & $<\mathrm{DL}$ & $<\mathrm{DL}$ \\
\hline Intestine (large) & 0.60 & 0.16 & 0.19 & 0.11 & 0.02 \\
\hline Intestine (small) & 3.09 & 0.49 & 0.10 & 0.02 & $<\mathrm{DL}$ \\
\hline Kidney & 4.72 & 2.25 & 1.66 & 1.17 & 0.51 \\
\hline Liver & 0.57 & 0.17 & 0.08 & 0.04 & $<\mathrm{DL}$ \\
\hline Lung & 0.73 & 0.06 & 0.03 & 0.02 & $<\mathrm{DL}$ \\
\hline Muscle & 0.18 & 0.03 & $<\mathrm{DL}$ & $<\mathrm{DL}$ & $<\mathrm{DL}$ \\
\hline Pancreas & 0.45 & 0.08 & 0.05 & 0.03 & $<\mathrm{DL}$ \\
\hline Renal cortex & 3.36 & 3.02 & 2.69 & 2.19 & 1.29 \\
\hline Renal medulla & 19.26 & 0.43 & 0.33 & 0.28 & 0.29 \\
\hline Salivary gland & 0.40 & 0.09 & 0.08 & 0.04 & 0.03 \\
\hline Skin and fur & 0.56 & 0.13 & 0.07 & 0.04 & $<\mathrm{DL}$ \\
\hline Spleen & 0.29 & 0.15 & 0.11 & 0.05 & 0.02 \\
\hline Stomach wall & 0.72 & 0.09 & 0.04 & 0.03 & $<\mathrm{DL}$ \\
\hline
\end{tabular}

$0.08 \%$ of Gd and $0.38 \pm 0.06 \%$ of DTPA-BMA were present in these samples.

\section{Discussion}

The aim of this investigation in rats was to study the fate of trace amounts of ${ }^{14} \mathrm{C}$-labelled GdDTPA-BMA in Omniscan, i.e. the commercial product administered to patients containing 5\% CaDTPA-BMA, after intravenous adminis- tration. By spiking the Omniscan solution before injection with $\mathrm{Gd}\left[{ }^{14} \mathrm{C}\right] \mathrm{DTPA}-\mathrm{BMA}$, it was possible to image the whole body biodistribution of the chelate DTPA-BMA. Moreover, the radiolabelled chelate and Gd could be estimated in the same tissue samples taken from the same animals as those used for QWBA. By spiking Omniscan (containing excess CaDTPA-BMA) with trace amounts of $\mathrm{Gd}\left[{ }^{14} \mathrm{C}\right] \mathrm{DTPA}-\mathrm{BMA}$, we could be sure that even if a small excess of Gd should be present in the laboratory-prepared $\mathrm{Gd}\left[{ }^{14} \mathrm{C}\right] \mathrm{DTPA}-\mathrm{BMA}$, it would be bound by the excess

Table 2 Estimated amounts of $\mathrm{Gd}(\mu \mathrm{g} \mathrm{Gd} / \mathrm{g}$ tissue) in selected organs/tissues from rats injected with Omniscan with trace amounts of ${ }^{14} \mathrm{C}$-labelled GdDTPA-BMA. Data are given as mean $\pm \mathrm{SD}(n=3)$

\begin{tabular}{llllll}
\hline Tissues & \multicolumn{5}{l}{ Time after injection } \\
\cline { 2 - 6 } & $1 \mathrm{~h}$ & $4 \mathrm{~h}$ & $24 \mathrm{~h}$ & 3 days & 7 days \\
\hline Kidney & $72.6 \pm 13.2$ & $36.5 \pm 7.58$ & $30.0 \pm 5.19$ & $23.6 \pm 1.04$ & $12.7 \pm 0.96$ \\
Liver & $7.40 \pm 2.11$ & $2.44 \pm 0.98$ & $1.56 \pm 0.21$ & $0.88 \pm 0.13$ & $0.53 \pm 0.15$ \\
Lung & $10.4 \pm 2.46$ & $1.75 \pm 1.01$ & $0.88 \pm 0.02$ & $0.71 \pm 0.09$ & $0.48 \pm 0.02$ \\
Muscle & $3.20 \pm 0.52$ & $0.55 \pm 0.11$ & $0.35 \pm 0.05$ & $0.21 \pm 0.01$ & $0.16^{\mathrm{a}}$ \\
Skin & $5.36 \pm 1.28$ & $1.22 \pm 0.28$ & $0.76 \pm 0.11$ & $0.52 \pm 0.12$ & $0.39 \pm 0.16$ \\
Bone & $6.05 \pm 1.62$ & $3.47 \pm 0.43$ & $3.55 \pm 0.19$ & $4.45 \pm 0.49$ & $4.92 \pm 0.11$ \\
\hline
\end{tabular}

${ }^{a}$ Only one sample above limit of quantitation 
Table 3 Estimated amounts of ${ }^{14} \mathrm{C}$-labelled substance (dpm/g tissue) in selected organs/tissues from rats injected with Omniscan with trace amounts of ${ }^{14} \mathrm{C}$-labelled GdDTPA-BMA. Data are given as mean $\pm \operatorname{SD}(n=3)$

\begin{tabular}{|c|c|c|c|c|c|}
\hline \multirow[t]{2}{*}{ Tissues } & \multicolumn{5}{|c|}{ Time after injection } \\
\hline & $1 \mathrm{~h}$ & $4 \mathrm{~h}$ & $24 \mathrm{~h}$ & 3 days & 7 days \\
\hline Kidney & $282,946 \pm 40,603$ & $134,611 \pm 29,011$ & $103,737 \pm 12,053$ & $80,438 \pm 3,540$ & $35,256 \pm 5,781$ \\
\hline Liver & $31,296 \pm 7,000$ & $9,548 \pm 3,075$ & $4,928 \pm 739$ & $2,421 \pm 207$ & $680 \pm 148$ \\
\hline Lung & $37,712 \pm 9,734$ & $6,522 \pm 4,262$ & $2,540 \pm 228$ & $1,441 \pm 177$ & $606 \pm 32$ \\
\hline Muscle & $14,896 \pm 3,746$ & $2,979 \pm 1,505$ & $1,515 \pm 334$ & $942 \pm 32$ & $490 \pm 50$ \\
\hline Skin & $20,023 \pm 4,090$ & $5,014 \pm 899$ & $2,828 \pm 268$ & $1,736 \pm 25$ & $933 \pm 172$ \\
\hline Bone & $18,179 \pm 8,852$ & $5,893 \pm 1,220$ & $3,275 \pm 102$ & $1,833 \pm 183$ & $908 \pm 150$ \\
\hline
\end{tabular}

chelate, upon injection to the animal, and therefore would not have any effect on the data obtained.

The whole-body autoradiography images show higher concentrations of radioactivity in the intervertebral discs of the spinal column, in the dermis of the skin, and as a rim surrounding large bones such as the femur compared with the surrounding tissues. It could not be determined whether the rim surrounding large bones is due to binding to the periosteum (connective tissue around the bone) or the bone surface. The data thus show that the agent enters different organs or organ compartments and the clearance kinetics is different from each.

Regarding discussions about NSF and the presence of Gd in skin, it should be noted that very similar concentrations of ${ }^{14} \mathrm{C}$ and $\mathrm{Gd}$ were present in the samples obtained during the first 3 days after injection. Thus, the measurements of $\mathrm{Gd}$ only in such samples cannot be used to quantify the amount of dechelation (release of Gd from the chelate), contrary to what often is described in the literature (see discussion below). Of the residual amount of the injected substance that was left in the rat 3 and 7 days $(0.75 \%$ and $0.54 \%$, respectively) after injection of Omniscan spiked with trace amounts of ${ }^{14} \mathrm{C}$-labelled GdDTPA-BMA, very small amounts of $\mathrm{Gd}$ (less than $0.2 \%$ of the injected dose) were not co-localised with the intact radiolabelled DTPA-BMA. Increased amounts of radioactivity in the oesophagus and intestine could be due to rats ingesting radiolabelled urine whilst grooming, as well as ingestion of radioactive stools by coprophagy (Fig. 2 , image $1 \mathrm{~h}$ post-injection). It was not possible to obtain reliable estimates of the amount of the injected dose that may have entered the animals via the oral route.

To our knowledge, measurements of both Gd and the chelate in tissue samples from the same animals have not been published for any of the other GBCAs on the market. The present data clearly show the importance of measuring both $\mathrm{Gd}$ and the chelate in tissues before drawing any conclusions about the stability of different agents in animal studies. It should be stressed that the present data were obtained using a single dose, which was close to that used clinically, contrary to much of the animal data reported in the literature for recovery of $\mathrm{Gd}$ in tissue samples, and which are often obtained following repeated injections of very high doses of Gd-chelates (up to 20 injections with 25 -times the standard clinical imaging dose [11, 12]).

The present data are important in relation to conclusions drawn in several earlier publications aimed at describing the stability of GBCAs. Firstly, we would like to stress that ICP-MS, or similar techniques such as ICP-AES, only measure the concentration of inorganic metals such as Gd, and cannot be used to assess whether or not Gd is still bound to the chelate without using additional methods. Despite this, there are several publications where this issue is not addressed, and where the presence of Gd in tissue samples obtained after intravenous injection is interpreted as evidence of dechelation of the agents. To rectify this deficiency in the published literature, our strategy was to combine ICP-AES/ICP-SF-MS measurements of $\mathrm{Gd}$, together with beta-counting of the radiolabelled chelate following injection of Omniscan-added trace amounts of $\mathrm{Gd}\left[{ }^{14} \mathrm{C}\right] \mathrm{DTPA}-\mathrm{BMA}$. Another possible approach is to use ICP-MS as a detector after chromatographic separation, but no such methods are available, probably because the tissue extraction method may interfere with the stability of the complex, thus leading to erroneous results.

As mentioned in the introduction, it is in principle possible to label the substance with ${ }^{153} \mathrm{Gd}$ and to use gamma-counting for estimation of the Gd concentration in tissue samples. However, our experience (unpublished data) is that labelling with ${ }^{153} \mathrm{Gd}$ causes radiolysis, which may destroy the chelate and cause release of Gd, leading to a gross overestimate of dechelation. Another challenge related to the use of ${ }^{153} \mathrm{Gd}$-labelled substance (if no excess chelate is added) is the quality control analyses needed to show that there is no free ${ }^{153} \mathrm{Gd}$ in the substance injected. It should be noted that any attempt to analyse for free Gd by chromatographic methods also includes the risk that the free Gd will bind to the column material, thus underestimating the amount of free Gd present in the solution. It is well known that following intravenous injection of $\mathrm{Gd}$ salts such as $\mathrm{GdCl}_{3}$ in animals, aggregates of $\mathrm{Gd}$ are formed and are taken up by the reticuloendothelial system, including the liver, spleen and bone marrow [17]. Therefore, even minor amounts of free Gd in formulations of GBCAs injected into animals may lead to significantly 

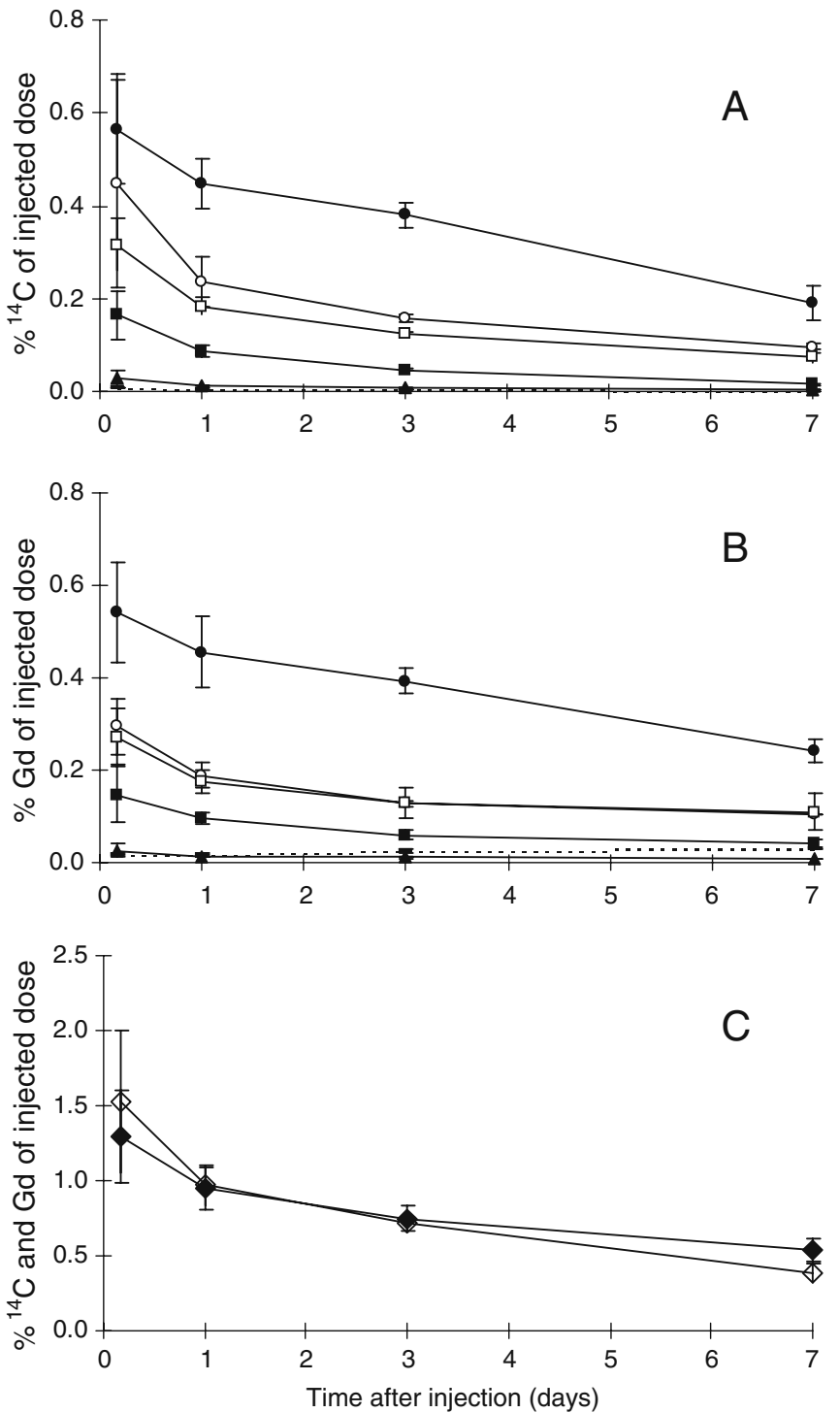

Fig. 3a-c Analyses of tissue homogenate samples obtained from kidney $(\bullet)$, liver $(\boldsymbol{\bullet})$, lung $(\boldsymbol{\Delta})$, muscle $(\circ)$, skin $(\square)$, and femur bone matrix (- with dotted line) at 4 and $24 \mathrm{~h}$, and 3 and 7 days after injection of Omniscan with trace amounts of $\mathrm{Gd}\left[{ }^{14} \mathrm{C}\right] \mathrm{DTPA}-\mathrm{BMA}$. a The percentage of injected dose of the radioactivity per organ is shown for all tissues at all time points. b The percentage of the injected dose of Gd is shown for all samples at all time points. $\mathbf{c}$ The sum of the radioactivity $(\diamond)$ and Gd $(\diamond)$ data for the six tissues shown in $\mathbf{a}$ and $\mathbf{b}$ is compared in the same plot. The 1-h data are not included in the figure in order to expand the $y$-scale for the later time points

increased uptake of Gd in these tissues, seriously interfering with the estimate of Gd uptake in tissue due to release from the chelate.

There are examples in the literature where the appropriate data to show the absence of free ${ }^{153} \mathrm{Gd}$ in the injection solution are not given, but despite this, the ${ }^{153} \mathrm{Gd}$ content of tissue samples is taken as evidence of released
Gd $[7,8]$. In addition, there are also studies with nonradiolabelled $\mathrm{Gd}$ where the presence of the metal in tissue samples is also interpreted as being due to $\mathrm{Gd}$ released from its chelate [9-12], although without also measuring the chelate. As shown from the present study, this cannot be taken as evidence of dechelation. Moreover, several authors have interpreted the $\mathrm{Zn}$ content in human urine following injection of various GBCAs to be due to differences in their stability [13, 14], without appreciating that the urine $\mathrm{Zn}$ content can be fully accounted for by $\mathrm{Zn}$ binding to the extra chelate present in the GBCA formulations (e.g. CaDTPA-BMA in Omniscan). Okazaki et al. [18] reported that $92 \%$ of CaDTPA-BMA injected into rats was excreted in urine in the same form as it was injected; approximately $7 \%$ was excreted as the ZnDTPA-BMA and approximately $1 \%$ as CuDTPA-BMA. By assuming a similar binding of $\mathrm{Zn}$ to CaDTPA-BMA in humans to that in rats, one should expect $7 \%$ of the injected dose of CaDTPA-BMA present in Omniscan to be excreted as ZnDTPABMA, corresponding to $0.35 \%$ of the injected dose of GdDTPA-BMA.

Several authors have reported increased concentrations of Gd in skin obtained from NSF patients, and have interpreted this as most likely to be due to accumulation within intracellular organelles, e.g. lysosomes, or to extracellular localisation of insoluble Gd phosphates [1921]. These authors did not consider the possibility of GBCAs taken up via endocytosis, e.g. in cells such as macrophages or fibroblasts. Further studies are needed to understand the exact localisation and form of Gd observed at these sites, as well as their relevance, if any, to the development of NSF.

In the present study we have investigated the fate of both $\mathrm{Gd}$ and chelate after intravenous injection of Omniscan spiked with Gd $\left[{ }^{14} \mathrm{C}\right] \mathrm{DTPA}-\mathrm{BMA}$ in normal male Sprague Dawley rats. It is not known to what extent the fate of the GBCA in rats resembles that in humans, or to what extent the slower excretion of GBCAs in patients with renal impairment will impact on the behaviour of GBCA following intravenous injection. Clearly, more work is needed to understand how GBCAs are linked to the aetiology of NSF.

\section{Conclusion}

To the best of our knowledge, the present investigation has for the first time measured the in vivo tissue concentration of both Gd and chelate (DTPA-BMA) after administration of Omniscan containing trace amounts of $\mathrm{Gd}\left[{ }^{14} \mathrm{C}\right] \mathrm{DTPA}-\mathrm{BMA}$. The clearance of both $\mathrm{Gd}$ and DTPA-BMA from tissue samples was practically identical. Most of the administered dose was excreted rapidly, with approximately $1 \%$ of the material still to be eliminated from the body at $24 \mathrm{~h}$. The clearance of 
${ }^{14} \mathrm{C}$-labelled substance and $\mathrm{Gd}$ was very similar in almost all tissue samples up to 3 days after injection. These data clearly show that measurements of $\mathrm{Gd}$ concentration in tissue samples cannot be used as a measure of $\mathrm{Gd}$ released from the chelate. Previous publications that have restricted tissue measurement to Gd only as an indication of in vivo dechelation should be reviewed in the light of the findings we have reported in this investigation.
Acknowledgements The authors would like to thank Stein Waagene, Merete Høyem, Kristin Landmark, Hanne Jensen, Gerd Torgersen and Anne Marie Hvoslef for technical assistance, and Derek Grant, Ben Newton and the late Dagfinn Løvhaug for discussions and critical review of the manuscript. We would like to dedicate this publication to the memory of our colleague Dagfinn Løvhaug who passed away unexpectedly in July 2009.

Open Access This article is distributed under the terms of the Creative Commons Attribution Noncommercial License which permits any noncommercial use, distribution, and reproduction in any medium, provided the original author(s) and source are credited.

\section{References}

1. Grobner T (2006) Gadolinium-a specific trigger for the development of nephrogenic fibrosing dermopathy and nephrogenic systemic fibrosis? Nephrol Dial Transplant 21:1104-1108

2. Thomsen HS, Morcos SK, Dawson P (2006) Is there a causal relation between the administration of gadolinium based contrast media and the development of nephrogenic systemic fibrosis (NSF)? Clin Radiol 61:905906

3. Broome DR, Girguis MS, Baron PW, Cottrell AC, Kjellin I, Kirk GA (2007) Gadodiamide-associated nephrogenic systemic fibrosis: why radiologists should be concerned. AJR Am J Roentgenol 188:586-592

4. Cowper SE (2007) Nephrogenic systemic fibrosis: a review and exploration of the role of gadolinium. Adv Dermatol 23:131-154

5. Penfield JG, Reilly RF (2008) Nephrogenic systemic fibrosis risk: is there a difference between gadoliniumbased contrast agents? Semin Dial 21:129-134

6. Rofsky NM, Sherry AD, Lenkinski RE (2008) Nephrogenic systemic fibrosis: a chemical perspective. Radiology 247:608-612

7. Wedeking P, Kumar K, Tweedle MF (1992) Dissociation of gadolinium chelates in mice: relationship to chemical characteristics. Magn Res Imaging 10:641-648
8. Tweedle MF, Wedeking P, Kumar K (1995) Biodistribution of radiolabeled, formulated gadopentetate, gadoteridol, gadoterate, and gadodiamide in mice and rats. Invest Radiol 30:372-380

9. Gibby WA, Gibby KA, Gibby WA (2004) Comparison of GdDTPA-BMA (Omniscan) versus Gd HP-DO3A (ProHance) retention in bone tissue by inductively coupled plasma atomic emission spectroscopy. Invest Radiol 39:138-142

10. White GW, Gibby WA, Tweedle MF (2006) Comparison of Gd(DTPABMA) (Omniscan) versus Gd(HP-DO3A) (ProHance) relative to gadolinium retention in human bone tissue by inductively coupled plasma mass spectroscopy. Invest Radiol 41:272-278

11. Sieber MA, Pietsch H, Walter J, Haider W, Frenzel T, Weinmann H-J (2008) A preclinical study to investigate the development of nephrogenic systemic fibrosis: a possible role for gadoliniumbased contrast media. Invest Radiol 43:65-75

12. Sieber MA, Lengsfeld P, Frenzel T, Golfier S, Schmitt-Willich H, Siegmund F, Walter J, Weinmann H-J, Pietsch H (2008) Preclinical investigation to compare different gadoliniumbased contrast agents regarding their propensity to release gadolinium in vivo and to trigger nephrogenic systemic fibrosis-like lesions. Eur Radiol 18:2164-2173

13. Puttagunta NR, Gibby WA, Smith GT (1996) Human in vivo comparative study of zinc and copper transmetallation after administration of magnetic resonance imaging contrast agents. Invest Radiol 31:739-742

14. Kimura J, Ishiguchi T, Matsuda J, Ohno R, Nakamura A, Kamei S, Ohno K, Kawamura T, Murata K (2005) Human comparative study of zinc and copper excretion via urine after administration of magnetic resonance imaging contrast agents. Radiation Med 23:322-326
15. Skotland T, Hustvedt SO, Oulie I, Jacobsen PB, Friisk GA, Langøy AS, Uran S, Sandosham J, Cuthbertson A, Toft KG (2006) NC100668, a new tracer for imaging of venous thrombolism: disposition and metabolism in rats. Drug Metab Dispos 34:111-120

16. Normann PT, Hustvedt SO, Storflor H, Hals P-A (1995) Preclinical safety and pharmacokinetic profile of gadodiamide injection. Clinical MRI 5:95-101

17. Spencer AJ, Wilson SA, Batchelor J, Reid A, Rees J, Harpur E (1997) Gadolinium chloride toxicity in the rat. Toxicol Pathol 25:245-255

18. Okazaki O, Kurata T, Yoshioka N, Hakusui H (1996) Pharmacokinetics and stability of caldiamide sodium in rats. Arzneim-Forsch/Drug Res 46:7983

19. High WA, Ayers RA, Chandler J, Zito $G$, Cowper SE (2007) Gadolinium is detectable within the tissue of patients with nephrogenic systemic fibrosis. J Am Acad Dermatol 56:21-26

20. Thakral C, Alhariri J, Abraham JL (2007) Long term retention of gadolinium in tissues from nephrogenic systemic fibrosis patient after multiple gadolinium-enhanced MRI scans: case report and implications. Contrast Media Mol Imaging 2:199-205

21. Abraham JL, Thakral C (2008) Tissue distribution and kinetics of gadolinium and nephrogenic systemic fibrosis. Eur J Radiol 66:200-207 